\title{
Electromagnetic, Morphological, and Electrical Characterization of POMA/Carbon Nanotubes-Based Composites
}

\author{
Simone de Souza Pinto ${ }^{1,2}$ and Mirabel Cerqueira Rezende ${ }^{1,2}$ \\ ${ }^{1}$ Institute of Science and Technology, Universidade Federal de São Paulo (UNIFESP), Rua Talim 330, São José dos Campos, SP, Brazil \\ ${ }^{2}$ Technological Institute of Aeronautics, Praça Mal do Ar Eduardo Gomes 50, São José dos Campos, SP, Brazil \\ Correspondence should be addressed to Simone de Souza Pinto; simonesouza.pn@gmail.com
}

Received 13 November 2016; Revised 27 December 2016; Accepted 29 December 2016; Published 16 February 2017

Academic Editor: Andrew R. Barron

Copyright (c) 2017 Simone de Souza Pinto and Mirabel Cerqueira Rezende. This is an open access article distributed under the Creative Commons Attribution License, which permits unrestricted use, distribution, and reproduction in any medium, provided the original work is properly cited.

\begin{abstract}
This study involves the preparation of conducting composites based on poly(o-methoxyaniline) (POMA) and carbon nanotubes $(\mathrm{CNT})$ and the evaluation of them as radar absorbing materials (RAM), in the frequency range of $8.2-12.4 \mathrm{GHz}$ (X-band). The composites were obtained by synthesis in situ of POMA in the presence of CNT $(0.1$ and $0.5 \mathrm{wt} \%$ in relation to the o-methoxyaniline monomer). The resulting samples-POMA/CNT- $0.1 \mathrm{wt} \%$ and POMA/CNT- $0.5 \mathrm{wt} \%$-were incorporated in an epoxy resin matrix in the proportion of 1 and $10 \mathrm{wt} \%$. FT-IR analyses show that the POMA was successfully synthesized on the CNT surface. SEM analyses show that the synthesized POMA recovered all CNT surface. Electrical conductivity measurements show that the CNT contributed to increase the conductivity of POMA/CNT composites $\left(1.5-6.7 \mathrm{~S} \cdot \mathrm{cm}^{-1}\right)$ in relation to the neat POMA $\left(5.4 \times 10^{-1} \mathrm{~S} \cdot \mathrm{cm}^{-1}\right)$. The electromagnetic characterization involved the measurements of complex parameters of electrical permittivity $(\varepsilon)$ and magnetic permeability $(\mu)$, using a waveguide in the X-band. From these experimental data reflection loss (RL) simulations were performed for specimens with different thicknesses. The complex parameters show that the CNT in the composites increased $\varepsilon$ and $\mu$. These results are attributed to the CNT network formation into the composites. Simulated RL curves of neat POMA and POMA/CNT in epoxy resin show the preponderant influence of POMA on all RL curves. This behavior is attributed to the efficient CNT recovering by POMA. RL results show that the composite based on $10 \mathrm{wt} \%$ of POMA/CNT- $0.5 \mathrm{wt} \%$ in epoxy resin ( 9 mm thickness) presents the best $\mathrm{RL}$ results $(\approx 87 \%$ of attenuation at $12.4 \mathrm{GHz})$.
\end{abstract}

\section{Introduction}

There is a growing interest in the electromagnetic radiation shielding and radar absorbing materials (RAM) areas due to the intense growth of high-performance electrical and electronic systems in commercial, military, and scientific fields [1]. As a result, the search for new materials with lower cost, lower weight, and ease of processing has increased [2-5].

RAM can be obtained from different materials, as long as they favor losses of the incident energy in the frequency range of microwaves. For example, any ferrites, carbon black, carbon nanotubes (CNT), and conducting polymers can be cited [3-7]. In this area, the conducting polymers have attracted significant attention due to the lower density in relation to ferrites and carbonyl iron, for example, and good electrical conductivity values. These characteristics have motivated their uses in RAM processing, rechargeable battery, catalysts, electrodes, and sensors [8]. Among the conducting polymers, the polyaniline (PAni) stands out. Derivatives based on substituted PAni, like poly(o-methoxyaniline) (POMA), present also potential interest, because they may improve the processability due to the decreased rigidity of the polymer chains as a result of the introduction of substituent groups [9]. The structural formula of POMA is shown in Figure 1 [10].

More recently, POMA and their composites with carbon black [10] and nanocomposites based on POMA/CNT [3$5,11]$ have been studied as RAM. The literature has mentioned that composites containing CNT present advantages in various applications, standing out in electronics, automotive, and aerospace sectors, with uses in electrostatic dissipation, electromagnetic interference (EMI), and electromagnetic shielding $[4,5,12]$. Improvements in materials processing 
<smiles>COC1=CC(=Nc2ccc(C(F)(F)F)cc2OC)C=CC1=Nc1ccc(N(C)c2ccc(N(C)C)c(OC)c2)c(OC)c1</smiles>

FIgURE 1: Structural formula of POMA [10].

are also mentioned, for example, in the aggregation of ceramic particles $[13,14]$. The increased use of CNT in RAM processing is due to the intrinsic characteristic of this class of materials, that is, its good electrical conductivity [12]. This characteristic promotes the interaction of CNT and, consequently, of their nanocomposites, with the electrical field of electromagnetic waves, making them good candidates for the RAM processing. Thus, the main idea in working with composites is to integrate different components and their properties in a single material [15].

In this work, composites based on POMA/CNT were obtained by in situ polymerization and they were characterized taking their electromagnetic, morphological, and electrical characteristics. The electromagnetic properties (electrical permittivity $(\varepsilon)$, magnetic permeability $(\mu)$, and reflection loss curves) of the POMA/CNT composite embedded in epoxy resin matrix were also evaluated in the frequency range of $8.2-12.4 \mathrm{GHz}$ (X-band). The reflection loss as function of different sample thicknesses was investigated by computational simulation.

\section{Materials and Methods}

2.1. Materials. The materials used in this study were omethoxyaniline (or o-anisidine) from Aldrich, with $99 \%$ of purity, ammonium persulfate $\left(\left(\mathrm{NH}_{4}\right)_{2} \mathrm{~S}_{2} \mathrm{O}_{8}\right)$ from Merck as oxidant, with $98 \%$ of purity, $1.0 \mathrm{~mol} \cdot \mathrm{L}^{-1}$-aqueous solution of $\mathrm{HCl}$ (Merck, with 37\% minimum acid content), carbon nanotubes, code CM-95/MWNT, from Korean Iljin Nanotech Co. Ltd., and a commercial bicomponent epoxy resin, type Araldite, attending the proportion 2:1 of resin : hardener (wt/wt).

2.2. Preparation of POMA/CNT Composite. The POMA used in this study was synthesized based on a route from literature [19] and presented in detail in a previous study [10]. The preparation of POMA/CNT composite was carried out by in situ polymerization of POMA in the presence of CNT. This procedure was based on the literature $[12,20]$ that suggests the use of ultrasound bath for the dispersion of CNT in aqueous solution of $\mathrm{HCl}(1 \mathrm{M})$. Already, in the present work, best results were obtained dispersing the CNT in the acid solution using an ultrasound probe (sonicator) at five intervals of $10 \mathrm{~min}$ with $25 \%$ of the maximum amplitude of the equipment $(750 \mathrm{~W}$ and $20 \mathrm{kHz})$, interspersed with $5 \mathrm{~min}$ without vibration. The CNT quantities in the reaction medium were 0.1 and $0.5 \mathrm{wt} \%$ in relation to the
TABLE 1: POMA/CNT composites prepared.

\begin{tabular}{lc}
\hline Binary composite & $\begin{array}{c}\text { CNT in relation to } \\
\text { o-anisidine monomer (wt } \%)\end{array}$ \\
\hline POMA/CNT-0.1\% & 0.1 \\
POMA/CNT-0.5\% & 0.5 \\
\hline
\end{tabular}

o-anisidine monomer. Two samples of binary composites were prepared, named POMA/CNT- $0.1 \%$ and POMA/CNT$0.5 \%$ (see Table 1 ).

\subsection{Preparation of POMA/CNT/Epoxy Resin Composite.}

The preparation of specimens used neat POMA and POMA/CNT-0.1\% and POMA/CNT- $0.5 \%$ composites in a commercial epoxy resin matrix. From each binary composite (POMA/CNT-0.1\% and POMA/CNT-0.5\%) two ternary composites were prepared in epoxy resin using $1 \mathrm{wt} \%$ and $10 \mathrm{wt} \%$. Table 2 describes the samples prepared in epoxy resin. The mixtures were poured into molds of dimensions of $23 \mathrm{~mm} \times 10 \mathrm{~mm} \times 9.0 \mathrm{~mm}$. These specimens meet the exact dimensions of the waveguide sample-holder used in electromagnetic characterization. These mixtures were also poured into molds of $15 \mathrm{~mm}$ of diameter and $1.5 \mathrm{~mm}$ of thickness for the electrical conductivity measurements.

\subsection{Characterization}

2.4.1. Fourier Transform Infrared Spectroscopy (FT-IR). FTIR analyses of samples (POMA and POMA/CNT) were performed in a Perkin-Elmer Spectrum 2000 spectrometer. The spectra were taken as an average of 32 scans with $2 \mathrm{~cm}^{-1}$ resolution in the range of 4000 to $400 \mathrm{~cm}^{-1}$, using $\mathrm{KBr}$ (0.8 mg of sample : $400 \mathrm{mg}$ of $\mathrm{KBr}$ ).

2.4.2. Scanning Electron Microscopy (SEM). SEM analyses of POMA and POMA/CNT composites were carried out in an equipment LEO, model $435 \mathrm{Vip}$. The samples were covered with a thin layer of gold.

2.4.3. Electrical Conductivity. Electrical conductivity measurements of the samples were performed using the fourtip method [21], with $1.27 \mathrm{~mm}$ distance between the tips. Measurements were performed in triplicate with equipment Cascade Microtech C4s-64 coupled to a Keithley 236 source, a multimeter and an ammeter, using specimens with $15 \mathrm{~mm}$ of diameter and $1.5 \mathrm{~mm}$ of thickness. The POMA and POMA/CNT (in powder) specimens were prepared in an uniaxial press, from Solab, with $1.5 \mathrm{t}$-force. The specimens of POMA/epoxy resin and POMA/CNT/epoxy resin were poured into molds (see Section 2.3). The measurements were carried out at room temperature.

2.4.4. Electromagnetic Characterization. Real and imaginary values of $\varepsilon$ and $\mu$ were experimentally obtained, in triplicate, using a rectangular waveguide in the frequency range of 8.2$12.4 \mathrm{GHz}$. A vector network analyzer, HP, model 8510C, fitted to a X-band calibration set WR 90, was used. The calculation 
TABLE 2: POMA/CNT/epoxy resin composites prepared.

\begin{tabular}{|c|c|c|c|}
\hline Samples & Additive in epoxy resin & Concentration of additive (wt\%) & Code \\
\hline 1 wt\%-POMA/epoxy resin & POMA & 1 & 1\%-POMA \\
\hline $10 \mathrm{wt} \%$-POMA/epoxy resin & POMA & 10 & 10\%-POMA \\
\hline $1 \mathrm{wt} \%$-(POMA/CNT-0.1\%)/epoxy resin & POMA/CNT-0.1\% & 1 & 1\%-(POMA/CNT-0.1\%) \\
\hline $10 \mathrm{wt} \%-(\mathrm{POMA} / \mathrm{CNT}-0.1 \%) /$ epoxy resin & POMA/CNT-0.1\% & 10 & 10\%-(POMA/CNT-0.1\%) \\
\hline $1 \mathrm{wt} \%$-(POMA/CNT-0.5\%)/epoxy resin & POMA/CNT-0.5\% & 1 & 1\%-(POMA/CNT-0.5\%) \\
\hline $10 \mathrm{wt} \%$-(POMA/CNT-0.5\%)/epoxy resin & POMA/CNT-0.5\% & 10 & 10\%-(POMA/CNT-0.5\%) \\
\hline
\end{tabular}

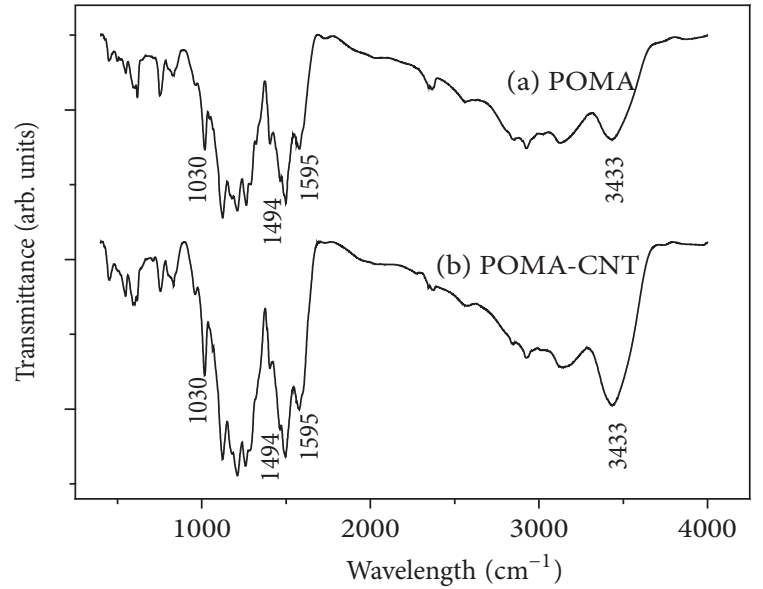

FIgURE 2: FT-IR spectra of (a) synthesized POMA and (b) POMA/ CNT composite.

of $\varepsilon$ and $\mu$ used software 85017E from Agilent, based on the model of Nicolson Ross [22].

The complex parameters $\varepsilon$ and $\mu$ are expressed by (1), considering the real and imaginary components of the permittivity $\left(\varepsilon^{\prime}\right.$ and $\left.\varepsilon^{\prime \prime}\right)$ and the permeability $\left(\mu^{\prime}\right.$ and $\left.\mu^{\prime \prime}\right)$, respectively.

$$
\begin{aligned}
& \varepsilon=\varepsilon^{\prime}-j \varepsilon^{\prime \prime}, \\
& \mu=\mu^{\prime}-j \mu^{\prime \prime} .
\end{aligned}
$$

Equation (2) gives the reflection loss (RL) using the normalized impedance $(Z)$ of the material. In this case, it is considered the normal incidence of the electromagnetic wave on the specimen, in the waveguide [23]:

$$
\mathrm{RL}(\mathrm{dB})=20 \log \left|\frac{Z-1}{Z+1}\right| .
$$

When the appropriate setting of the complex parameters of permeability and permittivity is reached we have the impedance matching and the RL is maximal for the material (for a given frequency and a given material thickness) [24].

2.5. Computer Simulation. RAM performance with different thicknesses in the X-band was evaluated by using a tool named "RFE" (an acronym in Portuguese for reflectivity, frequency, and thickness). This tool is a direct implementation of (1)-(2) as described in [23, 25]. The input parameters used in this tool are the experimental real and imaginary components of $\varepsilon\left(\varepsilon^{\prime}\right.$ and $\left.\varepsilon^{\prime \prime}\right)$ and $\mu\left(\mu^{\prime}\right.$ and $\left.\mu^{\prime \prime}\right)$, respectively, both in function of frequency. The output is the RL, in $\mathrm{dB}$, as a function of the range of frequencies of interest and the sample thickness, in $\mathrm{mm}$.

\section{Results and Discussion}

Figure 2 shows the FT-IR spectrum of the synthesized POMA. This spectrum shows contributions in the range of 3600 and $400 \mathrm{~cm}^{-1}$. The band at $3437 \mathrm{~cm}^{-1}$ is attributed to the formation of $\mathrm{NH}$ bonds due to the protonation of nitrogen, in accordance with the literature [16]. The contribution at $2800 \mathrm{~cm}^{-1}$ may be associated with both axial deformation of $\mathrm{C}-\mathrm{H}$ from aromatic carbon and also $\mathrm{C}-\mathrm{H}$ stretching of the $\mathrm{OCH}_{3}$ group in the polymeric chain [26]. The band at $1579 \mathrm{~cm}^{-1}$ is associated with quinoid (Q) structure and $1490 \mathrm{~cm}^{-1}$ band with benzenoid (B) structure. The presence of bands at $1500 \mathrm{~cm}^{-1}$ and $1600 \mathrm{~cm}^{-1}$ is also observed. According to the literature these contributions are related to the polymer formation from amine and imine units [26]. Table 3 summarizes the main infrared bands shown in Figure 2. The identification of the contributions is based on the literature [16-18].

Figure 2 shows also the FT-IR spectrum of the POMA/CNT composite. The comparison of the two spectra in Figure 2 shows that the CNT addition to the reaction medium increased the intensity of the bands related to the neat POMA, as observed at $1600 \mathrm{~cm}^{-1}, 1500 \mathrm{~cm}^{-1}$, and $3200 \mathrm{~cm}^{-1}$. These bands are characteristic of polyaniline and its derivatives, such as POMA, and are associated with the quinoid ring, vibration of benzene ring, and formation of $\mathrm{NH}$ bands, respectively [26]. In this case, it is observed that the structure at $1530 \mathrm{~cm}^{-1}$, relative to the $\mathrm{C}=\mathrm{C}$ group quinoid ring, and the band at $1074 \mathrm{~cm}^{-1}$ show a small shift in relation to the bands of neat POMA. At $2800 \mathrm{~cm}^{-1}$, POMA/CNT shows also the contribution previously observed for neat POMA. The observed displacement for any bands is assigned as the polymer interaction with the CNT structure. FT-IR results show the success of the in situ synthesis of POMA in the presence of CNT, indicating the synergy between the synthesized polymer and the carbonaceous structure of CNT. This good interaction is observed by increasing of intensity of FT-IR bands for the POMA/CNT composite. Such behavior is also cited in literature $[27,28]$.

Table 4 presents the electrical conductivity values of neat POMA, POMA/CNT, and their composites in epoxy resin. According to the literature, the addition of CNT in composites improves the electrical conductivity of end material [11, 
TABLE 3: Main FT-IR bands observed for POMA and POMA/CNT samples.

\begin{tabular}{|c|c|}
\hline Contribution $\left(\mathrm{cm}^{-1}\right)$ & Assignment (based on [16-18]) \\
\hline 3433 & Formation of $\mathrm{N}-\mathrm{H}$ bands attributed to protonation of the nitrogen \\
\hline 2800 & $\begin{array}{l}\text { Associated to both axial deformation of } \mathrm{C}-\mathrm{H} \text { from aromatic carbon and } \mathrm{C}-\mathrm{H} \text { stretching of the }-\mathrm{OCH}_{3} \text { group in } \\
\text { the polymeric chain }\end{array}$ \\
\hline 1595 & Group quinoid \\
\hline 1494 & $\mathrm{C}-\mathrm{N}$ stretch benzene \\
\hline 1462 & Stretch N, N \\
\hline 1247 & $\mathrm{C}-\mathrm{N}$ stretch in polaron structure (weak band in POMA) \\
\hline 1030 & SO stretch of ammonium persulfate used as a beginner's reaction \\
\hline 844,755 & Substituted 1, 2, 4 and aromatic substitution 1, 2, both associated with the methoxy group ortho monomer \\
\hline
\end{tabular}

TABLE 4: Electrical conductivity of studied samples.

\begin{tabular}{lc}
\hline Samples & $\sigma\left(\mathrm{S} \cdot \mathrm{cm}^{-1}\right)$ \\
\hline POMA & $5.4 \times 10^{-1}$ \\
POMA/CNT-0.1\% & 1.5 \\
POMA/CNT-0.5\% & 6.7 \\
1 wt $\%$-POMA & $\approx 0$ \\
$10 \%$-POMA & $\approx 0$ \\
$1 \%$-(POMA/CNT-0.1\%) & $\approx 0$ \\
$10 \%$-(POMA/CNT-0.1\%) & $\approx 0$ \\
$1 \%$-(POMA/CNT-0.5\%) & $\approx 0$ \\
$10 \%$-(POMA/CNT-0.5\%) & $\approx 0$ \\
\hline
\end{tabular}

12]. This observation is in agreement with the data presented in Table 4, where the electrical conductivity of POMA/CNT composite increased in comparison to the neat POMA values. According to Huang et al., 2007 [12], the electrical conductivity of the composite can be increased up to ten orders of magnitude, depending on the CNT amount in the reaction medium, due to the formation of percolating networks.

Table 4 shows that the POMA polymer presents the electrical conductivity value of $5.4 \times 10^{-1} \mathrm{~S} \cdot \mathrm{cm}^{-1}$. This value increases with the CNT increment in the formulation, reaching $6.7 \mathrm{~S} \cdot \mathrm{cm}^{-1}$ for the POMA/CNT composite containing 0.5 wt $\%$ of CNT (POMA/CNT-0.5\%).

On the other hand, the specimens prepared in epoxy resin behave as insulating material. This behavior can be attributed to two occurrences. In the first, the POMA and POMA/CNT concentrations used ( 1 and $10 \mathrm{wt} \%$ ) were not sufficient to achieve the percolation limit and the flow of charges was not favored. This hypothesis is less probable mainly for the formulation containing $10 \mathrm{wt} \%$ of POMA and POMA/CNT. In the second, the additives were not well dispersed in the epoxy resin. In addition, these additives were involved by epoxy resin making the final material with insulating characteristics.

Figure 3(a) shows a representative SEM micrograph of POMA. In this case the synthetized polymer presents morphology with flakes, platelets, and elongated shapes. Figure 3(b) shows a typical micrograph of CNT having a network of carbon filament bundles. Figures 3(c) and 3(d) are representative of POMA/CNT- $0.1 \%$ and POMA/CNT- $0.5 \%$
TABLE 5: Complex parameters of $\varepsilon$ and $\mu$ of the studied samples at $10 \mathrm{GHz}$.

\begin{tabular}{lcccc}
\hline Samples & $\varepsilon^{\prime}$ & $\varepsilon^{\prime \prime}$ & $\mu^{\prime}$ & $\mu^{\prime \prime}$ \\
\hline 1\%-POMA & 3.0481 & 0.0778 & 0.9882 & 0.0066 \\
10\%-POMA & 3.2169 & 0.1248 & 0.9904 & 0.0002 \\
1\%-(POMA/CNT-0.1\%) & 3.0675 & 0.1435 & 0.9611 & 0.0407 \\
10\%-(POMA/CNT-0.1\%) & 3.2720 & 0.1636 & 0.9902 & 0.0266 \\
1\%-(POMA/CNT-0.5\%) & 3.1020 & 0.1302 & 0.9892 & 0.0134 \\
10\%-(POMA/CNT-0.5\%) & 3.5762 & 0.2879 & 0.9899 & 0.0275 \\
\hline
\end{tabular}

composites, respectively. The analysis of this figure shows the presence of flakes and needle-shaped structures with dimensions between 2 and $6 \mu \mathrm{m}$, in a similar way to that one observed for POMA polymer (Figure 3(a)). Any needleshaped fragments are observed in Figures 3(c) and 3(d) as possible contribution of CNT pieces. But, in a general way, the presence of CNT filaments is not observed, as shown in Figure 3(b). This observation is assigned to an efficient POMA polymerization on the CNT surface. Similar observation is described in the literature [20].

Figures 4(a)-4(b) shows experimental complex parameters of $\varepsilon^{\prime}$ and $\varepsilon^{\prime \prime}$ of POMA/epoxy resin and POMA/CNT/ epoxy resin samples. Since the studied composite under consideration is dielectric type, the magnetic components $\mu^{\prime}$ and $\mu^{\prime \prime}$ vary around 1 and 0 , respectively, (Table 5) in accordance with the literature [29-31]. The analysis of Figure 4(a) shows that the storage component $\varepsilon^{\prime}$ of the composite is above 3 , decreasing with the frequency increasing as mentioned in the literature [29-31]. The increment of $\varepsilon^{\prime}$ with the POMA/CNT composite increasing in epoxy resin is expected, considering the electrical conductivity of POMA/CNT composites (Table 4). Figure 4(b) shows the behavior of the loss component $\varepsilon^{\prime \prime}$ as function of the X-band frequencies. It is also observed that this parameter increases for higher POMA/CNT contents in the epoxy resin, varying between 0.1 and 0.3 . Their decrease with the frequency increasing is also observed. These experimental parameters are useful because they allow predicting the RAM behavior in different both thicknesses and frequencies (up to $20 \mathrm{GHz}$ ). In this study, only the influence of thickness variation was investigated by computational prediction. Table 5 presents 


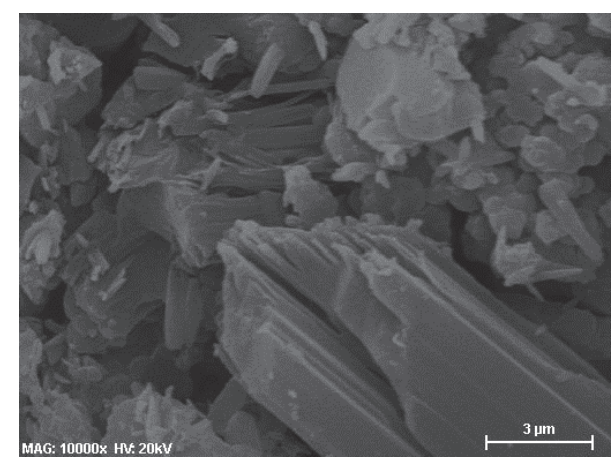

(a)

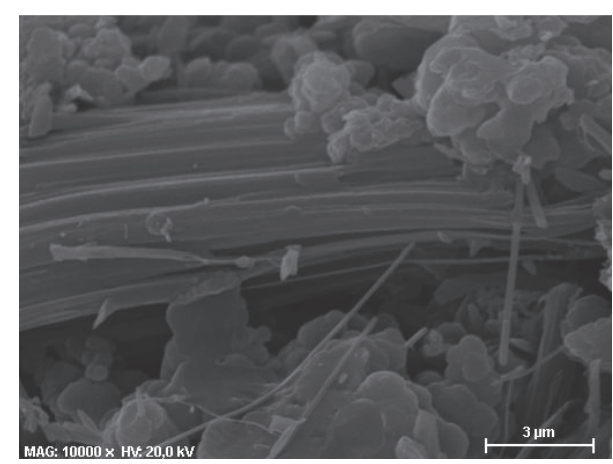

(c)

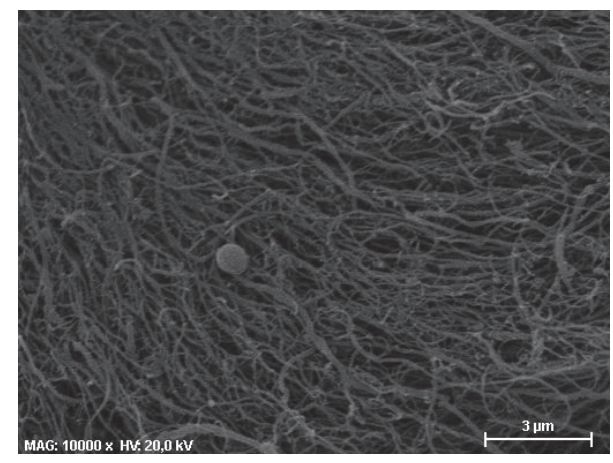

(b)

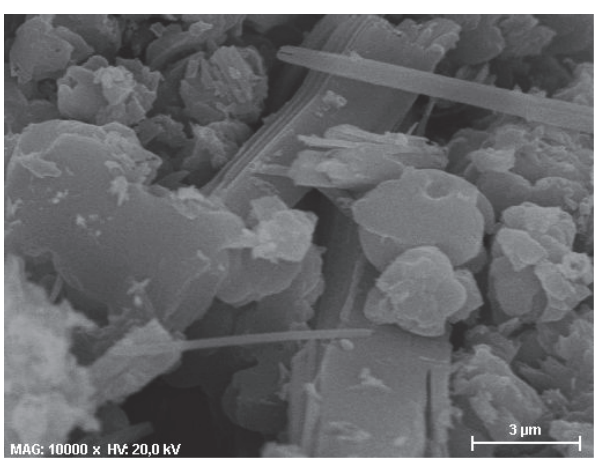

(d)

FIgure 3: SEM of (a) POMA, (b) CNT, (c) POMA/CNT-0.1\%, and (d) POMA/CNT-0.5\% (10000x).

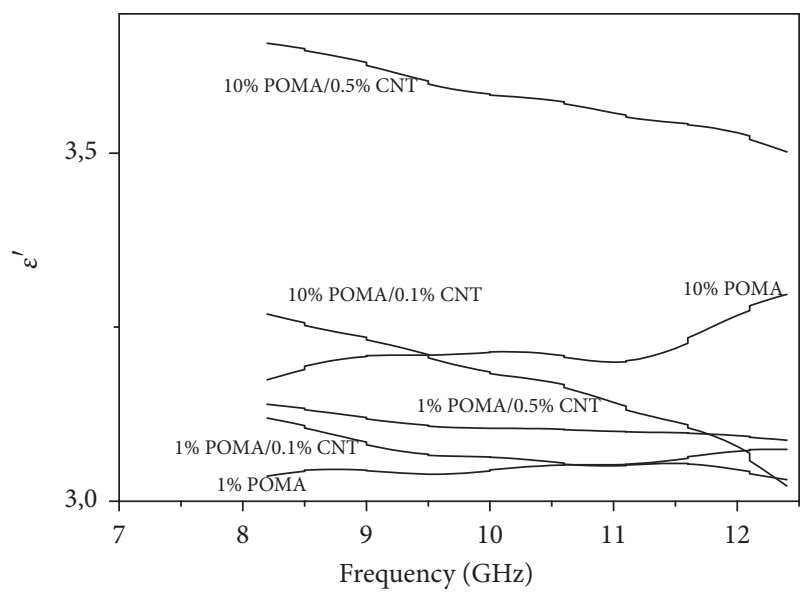

(a)

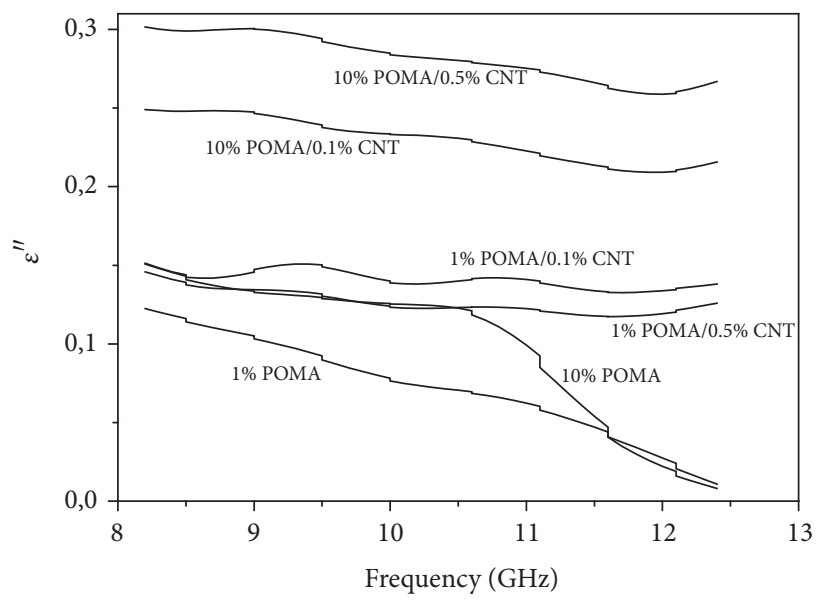

(b)

Figure 4: Complex parameters (a) $\varepsilon^{\prime}$ and (b) $\varepsilon^{\prime \prime}$ versus frequency of the composites.

experimental permittivity and permeability values of the investigated samples at $10 \mathrm{GHz}$.

The analysis of both complex parameters of $\varepsilon$ (Table 5) shows that the POMA content increasing in epoxy resin increases the values of the storage component from $\varepsilon^{\prime}=$ 3.0481 for $1 \%$-POMA to 3.2169 for $10 \%$-POMA, both at $10 \mathrm{GHz}$. In the same way, the loss component increases from $\varepsilon^{\prime \prime}=0.0778$ for $1 \%$-POMA to 0.1248 for $10 \%$-POMA, both at $10 \mathrm{GHz}$. Figure 4 and Table 5 show that the increment of $\mathrm{CNT}$ in the POMA/CNT composite contributes to increase these parameters also. In the same way, the increasing amount of POMA/CNT in the epoxy resin increases also the $\varepsilon$ parameters. For example, 10\%-(POMA/CNT-0.5\%) composite presents values of $\varepsilon^{\prime}=3.5762$ and $\varepsilon^{\prime \prime}=0.2879$, at $10 \mathrm{GHz}$. This behavior is attributed to the CNT network formed in the composite that favors the wave-material interaction $\left(\varepsilon^{\prime}\right)$ and the energy losses in the material $\left(\varepsilon^{\prime \prime}\right)$.

From these experimental values of $\varepsilon$ and $\mu$, obtained in the frequency range of 8.2 to $12.4 \mathrm{GHz}$ for all samples, computational simulations were performed to evaluate the 
influence of thickness on the performance of the sample studied as RAM. Previous work shows a good fit between simulated RL curves by RFE tool and those obtained experimentally [23]. Predicting RAM behavior based on simulation presents advantages, especially in reducing processing time and costs. Figure 5 shows simulated RL curves for the studied composites with thickness values of $2,4,6,8$, and $9 \mathrm{~mm}$.

The simulated RL curves (Figure 5) show that the RAM samples based on POMA and POMA/CNT composites, both in epoxy resin, present similar tendencies to attenuate microwaves in the X-band. The main difference observed in these curves is the attenuation intensity for each composition, with the main frequency of maximum attenuation almost the same. This behavior is attributed to the preponderance of POMA characteristics (morphological and electrical) on the processed RAM even those based on POMA/CNT. Comparing the electromagnetic behavior with SEM images (Figure 3) it is observed that the POMA/CNT composite shows similar morphology to that presented by neat POMA. This behavior indicates that the POMA characteristics prevailed on the wave-material interaction in the frequency band evaluated. Considering only the neat epoxy resin (without POMA and POMA/CNT), the RL curve shows transparent behavior of this polymeric matrix to the microwaves in $\mathrm{X}$-band, with values around zero dB.

The comparison of RL curves in Figures 5(a) and 5(b) shows that the increase of POMA content in epoxy resin (from 1 to $10 \mathrm{wt} \%$ ) contributed with slightly higher attenuation values for any thickness values, for example, 4 and $9 \mathrm{~mm}$. In this family of samples the attenuation values of POMA/epoxy resin specimens varied from -0.2 to $2.7 \mathrm{~dB}$ (up to $\sim 46 \%$ of attenuation). This behavior is attributed to the low electrical conductivity of POMA $\left(5.4 \times 10^{-1} \mathrm{~S} \cdot \mathrm{cm}^{-1}\right)$ and also to the POMA morphological aspects observed in this sample (Figure 3(a)). SEM of POMA shows the presence of flakes, platelets, and elongated shapes, which can make the dispersion and the contact difficult among the POMA particles.

More significant attenuation values are observed for the samples containing the POMA/CNT composites. In this case, both the increase of CNT in the POMA/CNT composite and the increase of POMA/CNT in epoxy resin resulted in higher attenuation values (Figures 5(c)-5(f)). The best attenuation results are observed for the sample $10 \mathrm{wt} \%$ POMA/CNT- $0.5 \%$ in epoxy resin, with $9 \mathrm{~mm}$ thickness. In this case, RL values up to $-9 \mathrm{~dB}(\approx 87 \%$ of attenuation) at $12.4 \mathrm{GHz}$ are observed. Figure $5(\mathrm{e})$ shows an experimental RL curve for a sample with $2 \mathrm{~mm}$ thickness. By comparing this experimental curve with the simulated RL curve (for the same thickness) it is observed that both present the same tendency of attenuation with small differences between them $(\sim 0.5 \mathrm{~dB})$.

When the CNT is present in the POMA/CNT composite the electrical conductivity increases, as shown in Table 2. However, in a general way, the samples prepared in epoxy resin behave as insulator material $(\sigma \approx 0)$. This behavior is attributed to the POMA and POMA/CNT recovering by epoxy resin, resulting in insulating samples. However, $\varepsilon$ parameters present increment in these values as shown in Figure 4 and Table 5. This behavior is explained by the dynamic conductivity of material $\left(\omega \varepsilon_{0} \varepsilon_{r}\right)$ [32].

The total electrical conductivity $\left(\sigma_{T}\right)$ of materials is composed by the static component $(\sigma)$ and the dynamic component $\left(\omega \varepsilon_{0} \varepsilon_{r}^{\prime \prime}\right)$, where $\omega$ is the angular frequency, $\varepsilon_{0}$ is the permittivity of vacuum, and $\varepsilon_{r}^{\prime \prime}$ is the relative imaginary permittivity, as follows [32]:

$$
\sigma_{T}=\sigma+\omega \varepsilon_{0} \varepsilon_{r}^{\prime \prime} .
$$

The correlation of electrical conductivity $(\sigma \approx 0)$ (Table 4), complex parameters of $\varepsilon$ (Figure 4 and Table 5), and the RL curves of the POMA/CNT-based RAM (Figure 5) prepared in this study allow attributing the microwave attenuation into the material by loss mechanics involving ionic, electronic, and/or dipolar polarization phenomena [31]. The resonant behavior observed in Figure 5 suggests also that the attenuation can be favored by wave cancelling, in function of the sample thickness $[30,31]$.

\section{Conclusions}

This study shows the preparation of conducting composites based on poly(o-methoxyaniline) (POMA) and carbon nanotubes (CNT) by synthesis in situ of POMA in the presence of CNT (0.1 and $0.5 \mathrm{wt} \%)$. FT-IR analyses show that the POMA synthesis occurred with success on the CNT surface with evidence of good interaction among these two components. SEM analyses show that the POMA morphology presents flakes, platelets, and elongated shapes. Similar aspects are observed in the POMA/CNT composites indicating the success of POMA synthesis on the CNT surface. Electrical conductivity measurements show that the CNT presence in the composites contributed to higher values of conductivity $\left(1.5-6.7 \mathrm{~S} \cdot \mathrm{cm}^{-1}\right)$ in relation to neat POMA $\left(5.4 \times 10^{-1} \mathrm{~S} \cdot \mathrm{cm}^{-1}\right)$. The complex parameters of $\varepsilon$ and $\mu$ measured in the $\mathrm{X}$ band increased with the CNT content in the POMA/CNT and also with the POMA/CNT content in epoxy resin. Computational simulations from experimental values of $\varepsilon$ and $\mu$ values showed the RL curves for samples with different thicknesses. Simulated RL curves of POMA and POMA/CNT in epoxy resin show the preponderant behavior of POMA on all curves, attributed to the recovering of all CNT surface, as shown in SEM analyses. RL results show that the composite based on $10 \mathrm{wt} \%$ of POMA/CNT- $0.5 \%$ in epoxy resin $(9 \mathrm{~mm}$ thickness) presents the best attenuation results with values up to $\approx 87 \%$ of attenuation, at $12.4 \mathrm{GHz}$. The results shows that the CNT improves the absorption properties probably due to the CNT network into the POMA/CNT composites.

\section{Competing Interests}

The authors declare that there is no conflict of interests regarding the publication of this paper.

\section{Acknowledgments}

The authors acknowledge the financial support received from FAPESP (Proc. 2010/09527-3; 2014/02551-7), CAPES/PVNS, 


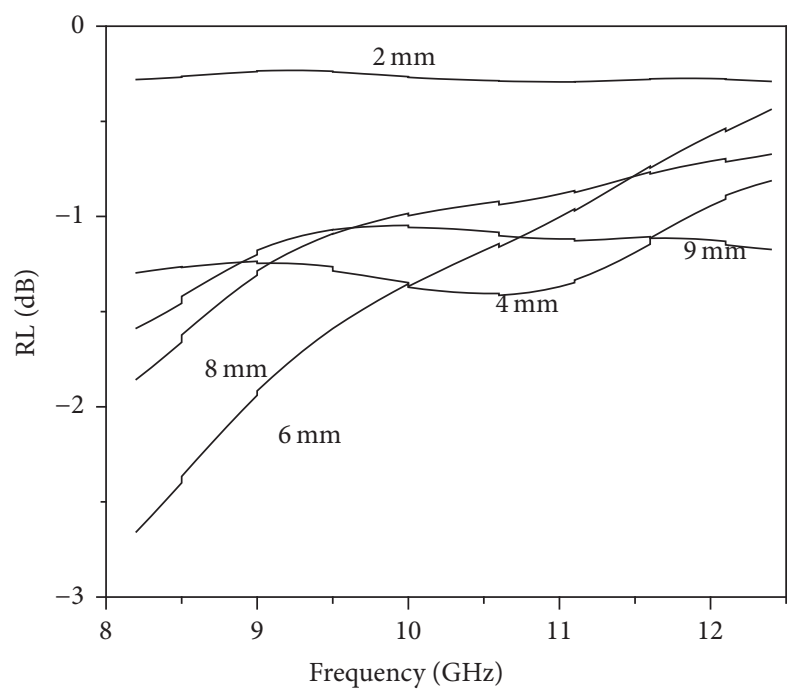

(a)

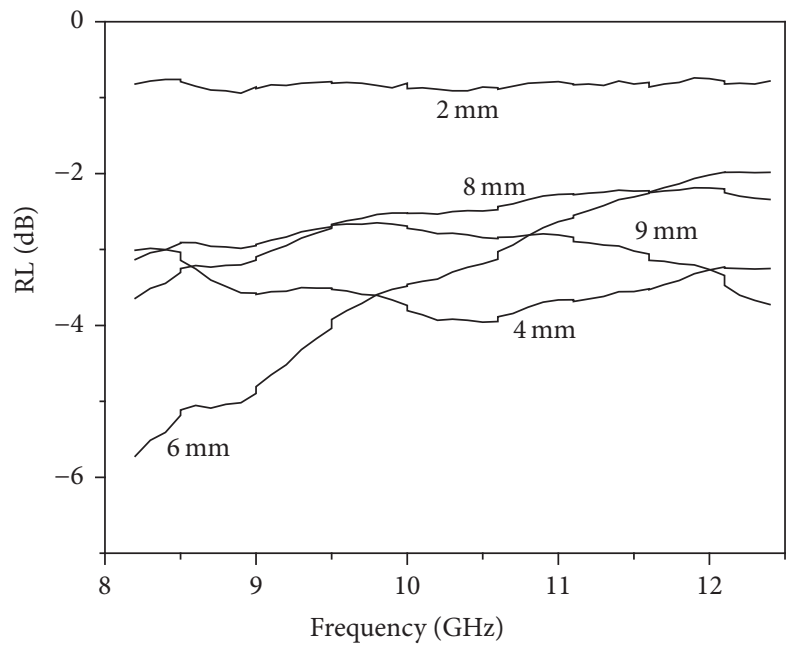

(c)

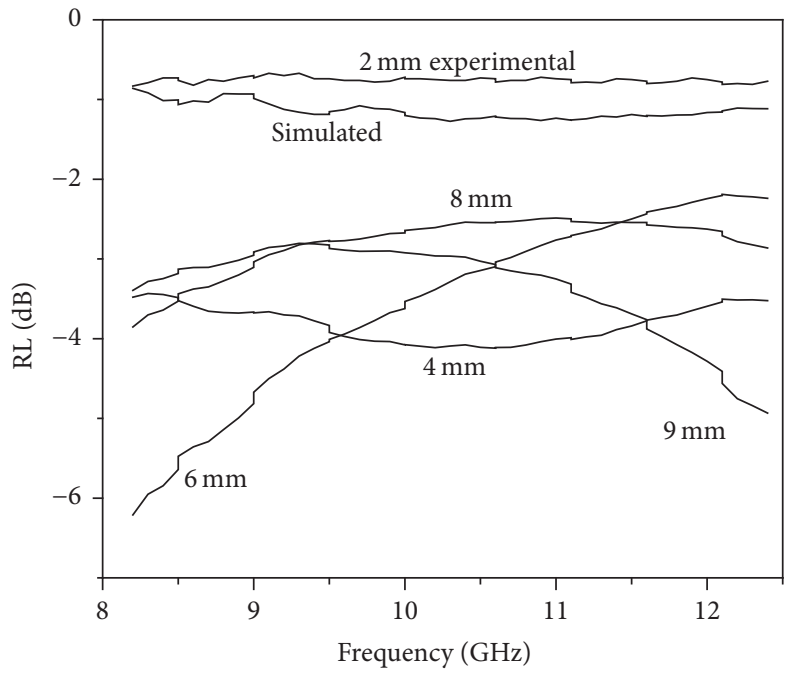

(e)

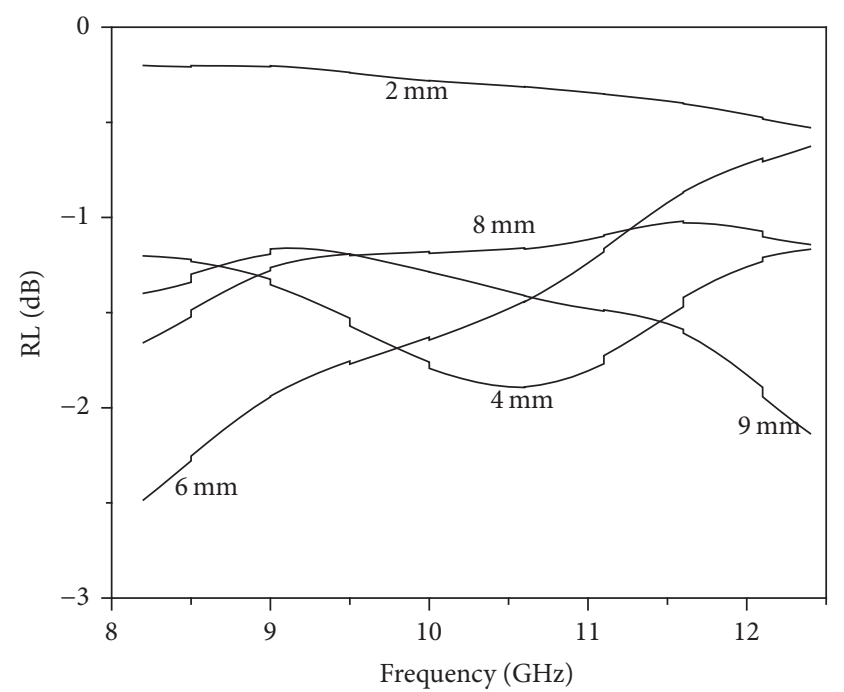

(b)

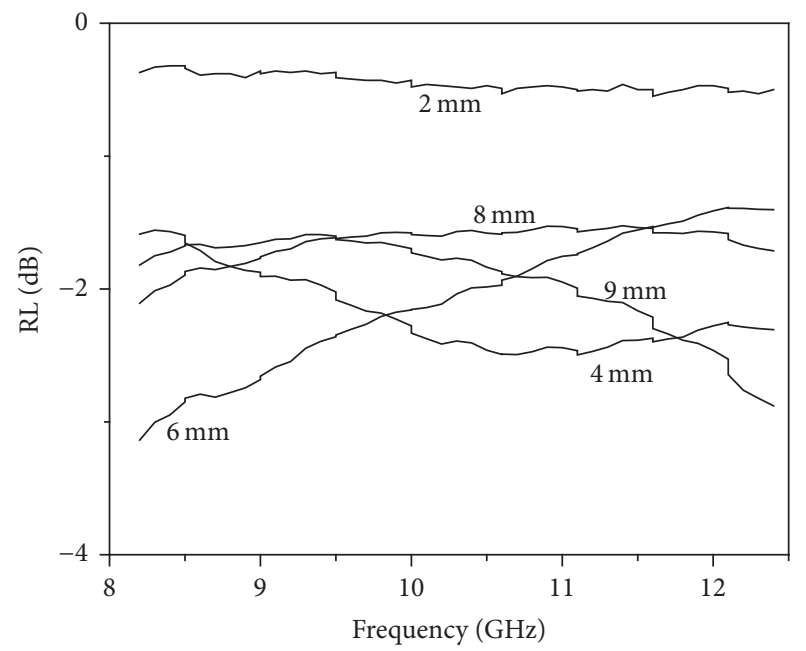

(d)

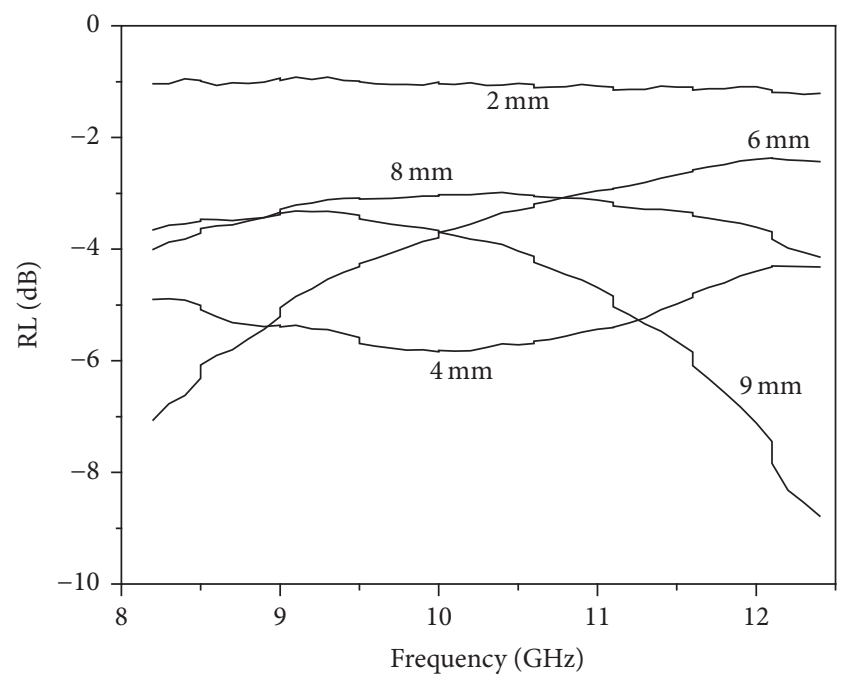

(f)

FIGURE 5: Simulated RL curves in the frequency range of 8.2 to $12.4 \mathrm{GHz}$ for (a) $1 \mathrm{wt} \%$-POMA, (b) 10 wt\%-POMA, (c) 1 wt\%-(POMA/CNT0.1\%), (d) $1 \mathrm{wt} \%-(\mathrm{POMA} / \mathrm{CNT}-0.5 \%)$, (d) $10 \mathrm{wt} \%-(\mathrm{POMA} / \mathrm{CNT}-0.1 \%)$, and (f) $10 \mathrm{wt} \%$-(POMA/CNT-0.5\%), all in epoxy resin. 
and CNPq (Proc. 303287/2013-6). The authors wish to express their gratitude to Dr. Christine C. Dantas from IAE/DCTA, Brazil, for providing the RFE tool for this study.

\section{References}

[1] B. R. Kim, H. K. Lee, E. Kim, and S.-H. Lee, "Intrinsic electromagnetic radiation shielding/absorbing characteristics of polyaniline-coated transparent thin films," Synthetic Metals, vol. 160, no. 17-18, pp. 1838-1842, 2010.

[2] M. Oyharçabal, T. Olinga, M.-P. Foulc, S. Lacomme, E. Gontier, and V. Vigneras, "Influence of the morphology of polyaniline on the microwave absorption properties of epoxy polyaniline composites," Composites Science and Technology, vol. 74, pp. 107-112, 2013.

[3] D. Micheli, C. Apollo, R. Pastore, and M. Marchetti, "X-Band microwave characterization of carbon-based nanocomposite material, absorption capability comparison and RAS design simulation," Composites Science and Technology, vol. 70, no. 2, pp. 400-409, 2010.

[4] D. Micheli, R. Pastore, A. Vricella et al., "Electromagnetic characterization and shielding effectiveness of concrete composite reinforced with carbon nanotubes in the mobile phones frequency band," Materials Science and Engineering B: SolidState Materials for Advanced Technology, vol. 188, pp. 119-129, 2014.

[5] D. Micheli, A. Vricella, R. Pastore et al., "Ballistic and electromagnetic shielding behaviour of multifunctional Kevlar fiber reinforced epoxy composites modified by carbon nanotubes," Carbon, vol. 104, pp. 141-156, 2016.

[6] W.-J. Lee, J.-W. Lee, and C.-G. Kim, "Characteristics of an electromagnetic wave absorbing composite structure with a conducting polymer electromagnetic bandgap (EBG) in the Xband," Composites Science and Technology, vol. 68, no. 12, pp. 2485-2489, 2008.

[7] M. S. Boon, W. P. Serena Saw, and M. Mariatti, "Magnetic, dielectric and thermal stability of NiZn ferrite-epoxy composite thin films for electronic applications," Journal of Magnetism and Magnetic Materials, vol. 324, no. 5, pp. 755-760, 2012.

[8] C. Wang, Y. Shen, X. Wang, H. Zhang, and A. Xie, "Synthesis of novel NiZn-ferrite/Polyaniline nanocomposites and their microwave absorption properties," Materials Science in Semiconductor Processing, vol. 16, no. 1, pp. 77-82, 2013.

[9] X. Wang, S. Ray, R. P. Cooney, P. A. Kilmartin, G. I. N. Waterhouse, and A. J. Easteal, "Synthesis and characterization of poly(o-methoxyaniline)-lignosulfonate composites," Synthetic Metals, vol. 162, no. 13-14, pp. 1084-1089, 2012.

[10] S. d. Pinto and M. C. Rezende, "Estudo da aplicação da poli(ometoxianilina) e de seus compósitos com negro de fumo no processamento de absorvedores de micro-ondas," Polímeros, vol. 22, no. 4, pp. 325-331, 2012.

[11] V. Bavastrello, T. B. C. Terencio, L. Belmonte, P. Cossari, and C. Nicolini, "Influence of substituents in electrochemical and conducting properties of polyaniline derivatives and multi walled carbon nanotubes nanocomposites," Thin Solid Films, vol. 520, no. 18, pp. 5877-5883, 2012.

[12] Y. Huang, N. Li, Y. Ma et al., "The influence of single-walled carbon nanotube structure on the electromagnetic interference shielding efficiency of its epoxy composites," Carbon, vol. 45, no. 8, pp. 1614-1621, 2007.

[13] V. Gomez, S. Alexander, and A. R. Barron, "Proppant immobilization facilitated by carbon nanotube mediated microwave treatment of polymer-proppant structures," Colloids and Surfaces A: Physicochemical and Engineering Aspects, vol. 513, pp. 297-305, 2017.

[14] V. Gomez, C. W. Dunnill, and A. R. Barron, "A microwave cured flux for the adhesion of ceramic particles using silica coated carbon nanotubes," Carbon, vol. 93, pp. 774-781, 2015.

[15] R. M. Khafagy, "Synthesis, characterization, magnetic and electrical properties of the novel conductive and magnetic Polyaniline/ $\mathrm{MgFe}_{2} \mathrm{O}_{4}$ nanocomposite having the core-shell structure," Journal of Alloys and Compounds, vol. 509, no. 41, pp. 9849-9857, 2011.

[16] S. Patil, J. R. Mahajan, M. A. More, and P. P. Patil, "Electrochemical synthesis of poly(O-methoxyaniline) thin films: effect of post treatment," Materials Chemistry and Physics, vol. 58, no. 1, pp. 31-36, 1999.

[17] X. Wang, S. Ray, M. Gizdavic-Nikolaidis, and A. J. Easteal, “The effects of dopant acids on structure and properties of poly(omethoxyaniline)," Journal of Polymer Science, Part A: Polymer Chemistry, vol. 50, no. 2, pp. 353-361, 2012.

[18] L. H. C. Mattoso, A. G. Macdiarmid, and A. J. Epstein, "Controlled synthesis of high molecular weight polyaniline and poly(o-methoxyaniline)," Synthetic Metals, vol. 68, no. 1, pp. 111, 1994.

[19] L. H. C. Mattoso and L. O. S. Bulhões, "Synthesis and characterization of poly(o-anisidine) films," Synthetic Metals, vol. 52, no. 2, pp. 171-181, 1992.

[20] V. Bavastrello, T. B. Correia Terencio, and C. Nicolini, "Synthesis and characterization of polyaniline derivatives and related carbon nanotubes nanocomposites-study of optical properties and band gap calculation," Polymer, vol. 52, no. 1, pp. 46-54, 2011.

[21] E. M. Girotto and I. A. Santos, "Medidas de resistividade elétrica DC em sólidos: como efetuálas corretamente," Química Nova, vol. 25, no. 4, pp. 639-647, 2002.

[22] A. M. Nicolson and G. F. Ross, "Measurement of the intrinsic properties of materials by time-domain techniques," IEEE Transactions on Instrumentation and Measurement, vol. 19, no. 4, pp. 377-382, 1970.

[23] A. M. Gama, M. C. Rezende, and C. C. Dantas, "Dependence of microwave absorption properties on ferrite volume fraction in MnZn ferrite/rubber radar absorbing materials," Journal of Magnetism and Magnetic Materials, vol. 323, no. 22, pp. 2782$2785,2011$.

[24] J. D. C. Dias, I. M. Martin, and M. C. Rezende, "Reflectivity of hybrid microwave absorbers based on NiZn ferrite and carbon black," Journal of Aerospace Technology and Management, vol. 4, no. 3, pp. 267-274, 2012.

[25] C. C. Dantas, M. C. Rezende, and S. S. Pinto, "A self-consistent extrapolation method for the complex permittivity and permeability based on finite frequency data," Journal of Computational Interdisciplinary Sciences, vol. 6, no. 1, pp. 3-20, 2015.

[26] N. S. Pereira, M. J. A. Sales, and A. M. Ceschin, "Studies of optical, morphological and electrical properties of POMA/ PMMA blends, using two different levels of doping with CSA," Polímeros, vol. 22, no. 4, pp. 384-389, 2012.

[27] K. H. Wu, T. H. Ting, G. P. Wang, W. D. Ho, and C. C. Shih, "Effect of carbon black content on electrical and microwave absorbing properties of polyaniline/carbon black nanocomposites," Polymer Degradation and Stability, vol. 93, no. 2, pp. 483488, 2008. 
[28] C. Peng, S. Zhang, D. Jewell, and G. Z. Chen, "Carbon nanotube and conducting polymer composites for supercapacitors," Progress in Natural Science, vol. 18, no. 7, pp. 777-788, 2008.

[29] M. H. Al-Saleh and U. Sundararaj, "Electromagnetic interference shielding mechanisms of CNT/polymer composites," Carbon, vol. 47, no. 7, pp. 1738-1746, 2009.

[30] C. Balanis, Advanced Engineering Electromagnetic, John Wiley \& Sons, 2nd edition, 2012.

[31] E. Knott, J. Scheffer, and M. Tuley, Radar Cross Section: Its Prediction, Measurement, and Reduction, Artech House, Dedham, Mass, USA, 6th edition, 1985.

[32] J. D. Kraus, Electromagnetics, McGraw-Hill, New York, NY, USA, 4th edition, 1991. 

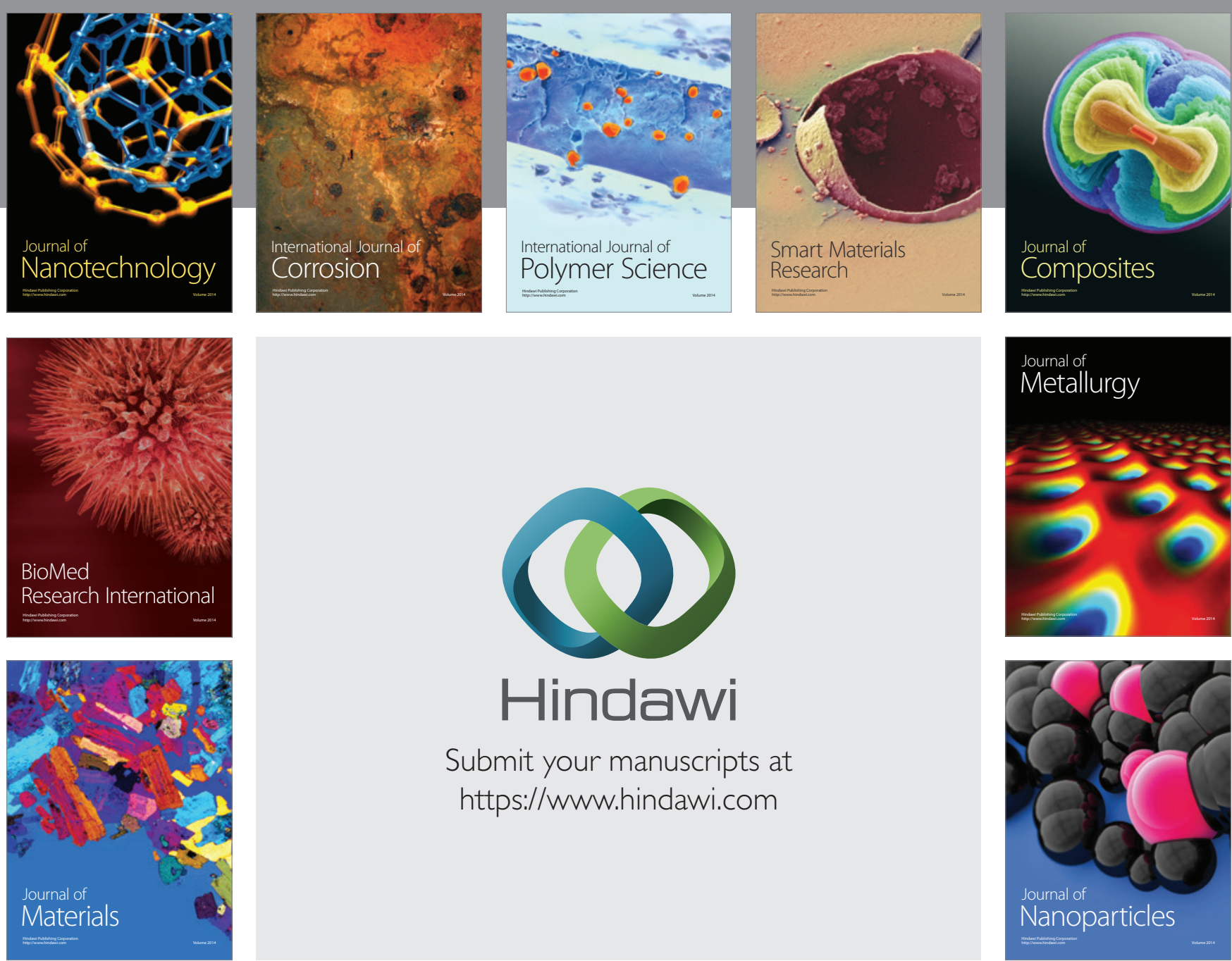

\section{Hindawi}

Submit your manuscripts at

https://www.hindawi.com

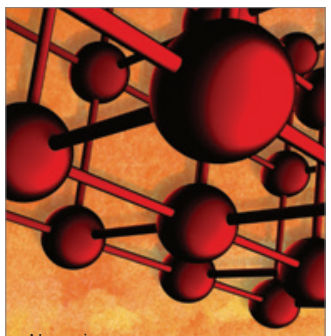

Materials Science and Engineering
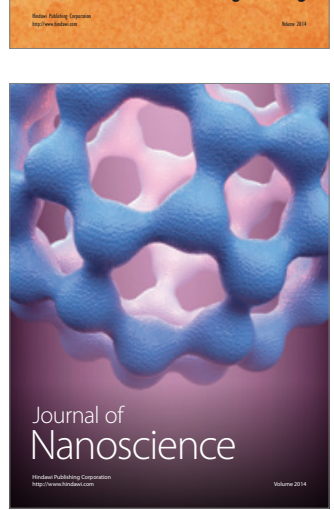
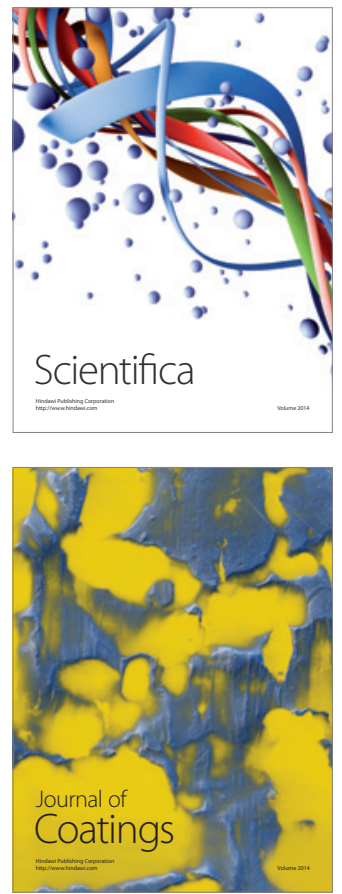
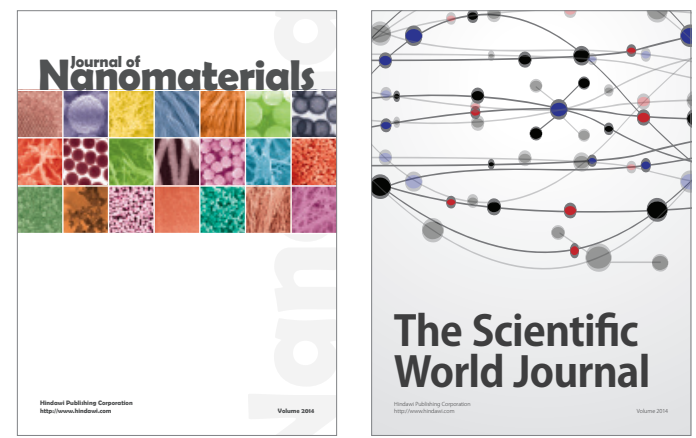

The Scientific World Journal
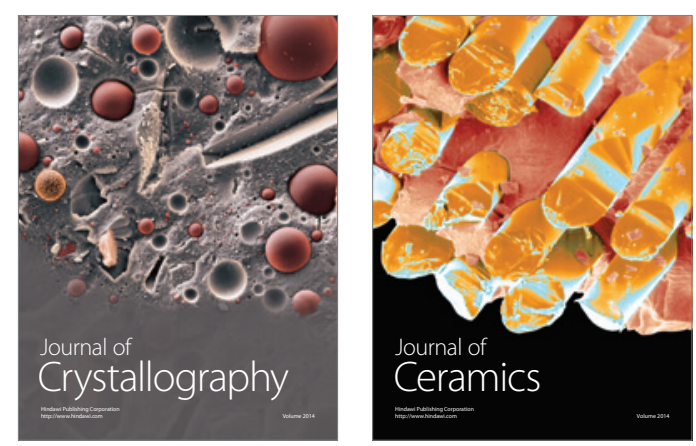
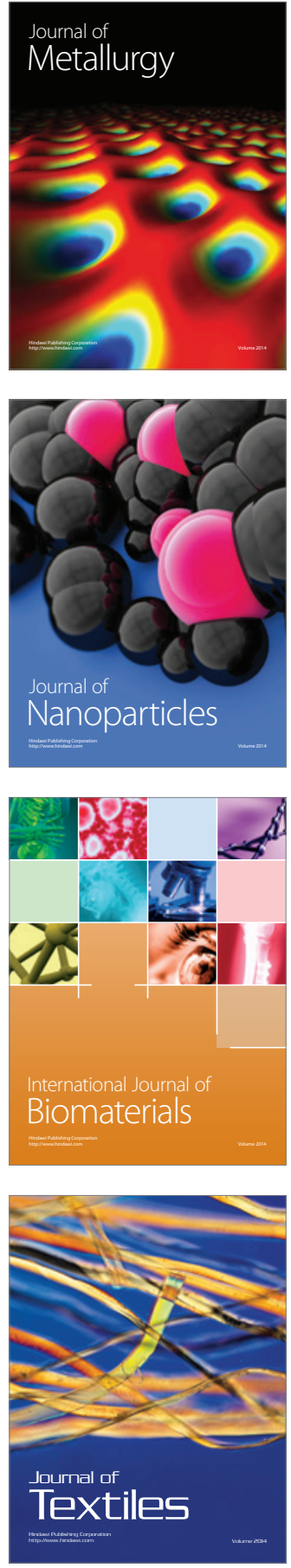